\title{
Editorial: North American Monarch Butterfly Ecology and Conservation
}

\author{
Jay E. Diffendorfer ${ }^{1 *}$, Wayne E. Thogmartin ${ }^{2}$, Ryan Drum ${ }^{3}$ and Cheryl B. Schultz ${ }^{4}$ \\ 1 Geosciences and Environmental Change Science Center, United States Geological Survey, Denver, CO, United States, \\ ${ }^{2}$ Upper Midwest Environmental Sciences Center, United States Geological Survey, LaCrosse, WI, United States, ${ }^{3}$ U.S. Fish \\ and Wildlife Service, Bloomington, MN, United States, ${ }^{4}$ School of Biological Sciences, Washington State University, \\ Vancouver, WA, United States
}

Keywords: Danaus plexippus, habitat restoration, population ecology, migration, monarch butterfly, monitoring, strategic habitat conservation

Editorial on the Research Topic

North American Monarch Butterfly Ecology and Conservation

OPEN ACCESS

Edited by:

Maria L. Pappas,

Democritus University of Thrace, Greece

Reviewed by:

Douglas Landis,

Michigan State University,

United States

*Correspondence:

Jay E. Diffendorfer jediffendorfer@usgs.gov

Specialty section:

This article was submitted to

Conservation,

a section of the journal

Frontiers in Ecology and Evolution

Received: 25 June 2020

Accepted: 25 August 2020

Published: 25 September 2020

Citation:

Diffendorfer JE, Thogmartin WE,

Drum R and Schultz CB (2020)

Editorial: North American Monarch

Butterfly Ecology and Conservation.

Front. Ecol. Evol. 8:576281.

doi: 10.3389/fevo.2020.576281
Spanning Canada, the United States, and Mexico, North America contains two populations of the migratory monarch butterfly (Danaus plexippus). The smaller "western" population overwinters in groves along the California coast and breeds west of the Rocky Mountains, while the much larger "eastern" population breeds east of the Rocky Mountains and overwinters in Oyamel fir forests in central Mexico. Both populations have declined in the last 20 to 30 years, leading to a formal petition in 2014 to list the species as threatened or endangered under the US Endangered Species Act (ESA) and a recommendation in 2016 for listing as endangered under the Canadian Species at Risk act.

The response to monarch declines in North America includes trinational (CAN, MEX, and USA) conservation agreements, federal and state management actions, non-governmental organizations programs, and concerted effort by individual citizens. The concomitant rise in science devoted to monarch ecology and conservation was the motivation for this Research Topic. The editors participated in the Monarch Conservation Science Partnership (MCSP) from 2014 to present and attended trinational monarch meetings sponsored by the Commission for Environmental Cooperation. The MCSP convened meetings including leading academic and government scientists from all three countries, managers from federal and state agencies, and representatives of conservation organizations to identify, prioritize, design, and apply science needed to conserve and recover the eastern and western migratory monarch populations. These scientific endeavors were a holistic approach, encompassing all elements of strategic habitat conservation (biological planning, conservation design, habitat delivery, monitoring, and assumption-driven research, National Ecological Assessment Team, 2006), and collectively serve to strengthen the scientific foundation for the impending threatened or endangered listing decisions.

This Research Topic expands on some of the work stemming from the MCSP as well as contributions from a much larger international scientific community. We purposely cast a broad net, inviting scientists and practitioners working on all aspects of monarch ecology and conservation, with the intent of illuminating the front lines of monarch conservation science prior to the listing decision. We sent out an open invitation and personally invited 67 scientists who had published research on monarchs or monarch habitat. Ultimately 34 articles were published by $>150$ authors. This is a subset of monarch-related research, reflecting widespread efforts to equip decision makers with the best available science to inform the listing process. Based on a Web of Science search for either "monarch butterfly" OR "Danaus plexippus" from 2017 to 2019, scientists published over 200 papers on topics related to monarch biology and conservation (55 in 2017, 64 in 
2018, and 96 in 2019). This collection in Frontiers includes basic monarch ecology and population dynamics, social science on attitudes toward monarch conservation, and the conservation and restoration of breeding, migratory and overwintering habitats.

Collectively, these papers demonstrate a vibrant, international community of scientists working diligently to fill key knowledge gaps associated with monarchs and their habitat. Much of this science is uniquely co-produced with managers and decision makers working alongside scientists. Like many species of concern, this work covers four main themes: habitat identification, management and restoration; population ecology; monitoring populations and habitats; and human dimensions and policy.

\section{HABITAT}

Monarch habitat, including breeding, overwintering, and migratory, is perhaps the largest focus of conservation efforts. In Mexico and coastal California, maintaining overwintering habitat and managing for climate change motivated some of our contributions. Forest cover loss in Mexican overwintering areas has been greatly reduced, due to shared conservation efforts with local communities (Flores-Martínez et al.), though some deforestation continues. In addition, contributions suggest reforestation practices using nurse plants enhance seedling survival of Oyamel fir (Carbajal-Navarro et al.) and new strategies for reforestation are constantly being improved (Guzmán-Aguilar et al.).

The loss of breeding habitat is considered a primary cause of decline for both eastern and western populations (Pleasants and Oberhauser, 2013; Flockhart et al., 2015; Oberhauser et al., 2017; Pleasants, 2017; Pelton et al.; Wilcox et al.) and so identification, conservation, and restoration of breeding habitat is a key management concern. Identifying habitat remains a key issue for the western population and Dilts et al. developed a seven-state map of non-overwintering habitat, demonstrating that habitat suitability is structured by both host plant habitat associations and climate variables. Waterbury et al. identified key breeding habitat in Idaho and Montana and showed, based on phenology, that it could support two or three generations of breeding per year. Finally, Svancara et al. suggested breeding habitat in Idaho may remain relatively stable under climate change given contrasting patterns of expansion and contraction of different milkweed species distributions.

For the entirety of North America, Castañeda et al. developed monthly distribution maps for monarchs, identifying key migratory habitat and showing large contractions of suitable areas from April to December during the monarch life cycle. Semmens and Ancona showed riparian buffer strips could make substantial contributions to monarch breeding habitat, while Johnston et al., Derby Lewis et al., and Baker and Potter emphasized various contributions of urban environs in conserving monarchs given the potential for high-density milkweed and nectar source plantings.
Restoring and managing breeding habitat is an area of active research. Contributions suggested monarch females lay more eggs on $A$. incarnata and $A$. syrica than other milkweed species in Iowa, emphasizing we need more studies on how monarchs select milkweed (Pocius et al.). In addition, adult monarchs have higher abundances in burned than in heavily grazed prairies, and high cattle stocking levels may negatively impact monarchs (Leone et al.). Haan and Landis argued more generally that implementing disturbance regimes into management may improve monarch habitat and called for more research on this topic. Lukens et al. demonstrated conserved grasslands provide much higher densities of milkweeds than previously thought and began to tease apart important relationships between management practices and habitat responses.

\section{POPULATION ECOLOGY AND MIGRATION}

The monarch life cycle is a multi-generational, spatially complex process taking place across many habitats that involves both longdistance migration and a long period of diapause. Fundamental processes driving migration and population dynamics remain important areas of study, as does predicting population dynamics through time and understanding how populations are impacted by threats and will respond to management actions. Wilcox et al. reviewed the existing literature on demography and threats to the eastern population and concluded breeding and overwinter habitat loss, in addition to a decline in suitable environmental conditions, are the most likely threats to longterm viability. Nail et al. described the global distribution of the species, recording over 90 countries, islands, and island groups where monarchs occur; they also discussed important differences in morphology, migration, overwintering behavior, natural enemies, larval diet, and genetics among these populations. Pelton et al. describe the $97 \%$ decline in historical abundance of the western monarch population and argue it may be nearing an extinction vortex. Crewe et al. teased apart the role of migration vs. summer breeding factors on monarchs in southern Canada; they found that the Canadian population is likely affected by variation in reproductive condition caused by weather conditions experienced during the spring migration. They also found a strong correspondence between breeding population sizes in Canada and the following overwintering population size in Mexico. Larval exposure to pesticides has been identified as a potential threat to monarchs. Olaya-Arenas and Kaplan found 14 pesticide residues in milkweed plants near neighboring croplands; they also found high levels of spatiotemporal variation in pesticide occurrence and called for more detailed studies that can better evaluate risk to monarchs. Within the eastern population's breeding habitat, Dinsmore et al. studied factors affecting site occupancy, colonization, and extinction dynamics; occupancy declined at sites with high woodland cover while extinction and colonization of sites were driven by landscape attributes and site-level habitat.

Models of population and movement dynamics have added to our understanding of monarch populations and risk of decline (Grant and Bradbury). Voorhies et al. continued this work by 
developing a modeling methodology and tool linking monarch population responses to specific threats or conservation actions for both the eastern and western populations. Scenarios of future monarch populations suggested a continued declining trend, even in best-case scenarios. Thogmartin et al. pointed out how high variability in the eastern monarch overwintering population size makes trend detection difficult; they showed that the recently reported increase in overwintering population size, while a positive result for monarch conservation, does not have sufficient statistical support to suggest an increasing trend in the population.

Two contributions focused on migration. Taylor et al., analyzed citizen science tagging data to suggest that the timing and pace of fall migration is consistent with monarchs seeking a constant sun angle at solar noon and that successful migrants fall within a sun angle window of 57 degrees at the beginning to 46 degrees at the end of the fall migration. Mora Alvarez et al. estimate $\sim 200,000$ monarchs are killed per season where they migrate across roads in two locations in Mexico. It is the first quantitative assessment of monarch road kills in Mexico.

\section{MONITORING}

Different aspects of monarch biology and its population status have been monitored for some time. For example, overwintering areas in Mexico and California have been routinely monitored since 1994 and 1997 respectively, while community science efforts monitor larvae (Monarch Larva Monitoring Program), the movement of tagged (Monarch Watch) and untagged (Journey North) adults, as well as sightings of immatures and adults throughout the year (iNaturalist and Western Monarch Milkweed Mapper). Efforts to develop a statistically rigorous monitoring program and rapid assessments that facilitate ease of data collection in breeding areas in the eastern breeding population are described by Cariveau, Anderson et al. and Cariveau, Holt et al. and included input by field biologists, monarch specialists, statisticians, land managers, and the US Fish and Wildlife Service. Similarly, Kinkead et al. analyzed monarch densities from a statewide inventory and monitoring program in Iowa and produced the first statewide density estimate of monarchs on breeding grounds. Monitoring of habitat in conservation sites (Flores-Martínez et al.; Lukens et al.) and along roadsides (Cariveau, Anderson et al.) will also be needed to understand how monarchs interact with these areas and how they support overwintering success, reproduction, and migration.

Two contributions describe relatively novel technological advances that may assist in both monitoring population status and other areas of monarch biology. Hristov et al. demonstrated ground-based lidar holds promise as a technology for surveying clusters of overwintering monarchs in both the US and Mexico. Hobson et al. investigated the utility of stable oxygen isotopes as a potential addition to the more commonly used stable hydrogen and carbon isotopes for inferring natal origins of adult monarchs found at overwintering sites.

\section{SOCIAL ISSUES AND MONARCHS}

The monarch is an iconic species in North America, having deep cultural significance in Mexico and high levels of public support and interest in the US and Canada. An imbalance exists between rural and urban areas across the monarch range, with rural areas supplying the bulk of habitat supporting monarchs but people living in urban areas reaping the benefits (Semmens et al., 2018). Using a survey of citizens from the US and Canada along the eastern flyway, Solis-Sosa et al. showed that garnering support of urbanites for monarch conservation can be maximized if such support is led by a not-for-profit organization, strives for transboundary cooperation, and includes communication about anticipated ecological outcomes.

\section{CONCLUSIONS}

Despite being one of the most-studied insects in the world, many important scientific mysteries of monarch butterflies remain, particularly regarding processes driving monarch population dynamics, the effectiveness of broad-scale conservation efforts, and related human dimensions in conservation policy. This system is incredibly complex. Data are limited and driving processes are very difficult to isolate. Thus, a great deal of important and challenging work remains-both in terms of scientific research and conservation work needed on the ground.

Moving forward, tackling the most important issuestracking the status and trends of the population throughout the annual cycle, better understanding western population dynamics, evaluating the effectiveness of conservation efforts, predicting and responding to climate change, and understanding other potential threats-will increasingly rely on collaborative partnerships. Successful collaborations will depend on ongoing coordination, leveraged funding/capacity, data sharing and interdisciplinary synthesis, community science contributions, technological innovations, and expanded applications of social science.

Regardless of forthcoming federal listing decisions in the US and Canada, it appears that this iconic species-and the fascinatingly complex system it inhabits-will continue to offer a prolific arena for applied conservation research. Recent efforts, including those resulting from the MCSP alongside many of the collaborations highlighted in this collection, offer a holistic and integrated framework, linking extinction risk to habitat goals at various scales. This framework was developed alongside a long-term monitoring strategy and directly tied to plans and tools that can guide strategic conservation planning and adaptive management throughout the annual cycle. Viewed as a whole, this framework and guidance is the cutting edge of monarch science and arguably represents the most robust, strategic and timely scientific foundation for applied decision-making possible at this time.

The advances captured in this Research Topic build on decades of successful research, standing on the shoulders of giants such as Lincoln Brower (Oberhauser et al.), among other pioneers of the field. Yet this progress also provides a fresh glimpse into the future frontiers of monarch conservation science. Scanning 
the horizon, we see a vibrant and increasingly international collaborative research community, an integrated and holistic approach guiding strategic conservation, exciting innovations drawing from interdisciplinary technological advancements, long-term biological monitoring data empowering new opportunities, and a growing awareness of the importance of social science woven into any foreseeable conservation solutions.

The state-led Mid-America Monarch Conservation Strategy (Midwest Association of Fish Wildlife Agencies, 2018) and the Western Monarch Butterfly Conservation Plan (Western Association of Fish Wildlife Agencies, 2019) offer reasons for cautious optimism. Furthermore, the recently signed candidate conservation agreement for monarchs on energy and transportation lands in the US provides a mechanism for habitat conservation and restoration intended to provide a net benefit for monarchs (Monarch CCAA/CCA Development Advisory Team, 2020). These plans and agreements portray the magnitude of both the opportunities and the challenges ahead. The ongoing implementation of these plans serves as a massive real-time experiment, offering a unique and timely opportunity to learn more about the drivers of the system and the effectiveness of our conservation interventions. Successfully capitalizing on this opportunity will require broad-scale collaboration to design research and implement long-term conservation, management, and monitoring efforts. This effort is no easy task to realize. For those mobilizing monarch conservation on the ground and

\section{REFERENCES}

Flockhart, D. T. T., Pichancourt, J. B., Norris, D. R., and Martin, T. G. (2015). Unravelling the annual cycle in a migratory animal: breeding-season habitat loss drives population declines of monarch butterflies. J. Anim. Ecol. 84, 155-165. doi: 10.1111/1365-2656. 12253

Midwest Association of Fish and Wildlife Agencies (2018). Mid-America Monarch Conservation Strategy, 2018-2038, Version 1.0. Available online at: http://www. mafwa.org/wp-content/uploads/2018/07/MAMCS_June2018_Final.pdf.

Monarch CCAA/CCA Development Advisory Team (2020). Nationwide Candidate Conservation Agreement for Monarch Butterfly on Energy and Transportation Lands: An Integrated Candidate Conservation Agreement with Assurances (CCAA) and Candidate Conservation Agreement (CCA). Prepared for monarch CCAA/CCA development advisory team, Energy Resources Center, and University of Illinois at Chicago. Prepared by Cardno, Inc, 95. Available online at: https://www.fws.gov/savethemonarch/pdfs/Final_CCAA_ 040720_Fully\%20Executed.pdf.

National Ecological Assessment Team (2006). Strategic Habitat Conservation: A Report From the National Ecological Assessment Team. Washington, DC; Reston, VA: U.S. Fish and Wildlife Service; U.S. Geological Survey. Available online at: https://www.fws.gov/landscape-conservation/pdf/SHCReport.pdf.

Oberhauser, K., Wiederholt, R., Diffendorfer, J. E., Ries, L., Lopez-Hoffman, L., Semmens D., et al. (2017). A trans-national monarch butterfly population model for identifying regional conservation priorities. Ecol. Ent. 42, 51-60. doi: $10.1111 /$ een.12351

Pleasants, J. (2017). Milkweed restoration in the Midwest for monarch butterfly recover: estimates of milkweeds lost, milkweeds remaining and milkweeds that must be added to increase the monarch population. Ins. Cons. Div. 10, 42-53. doi: 10.1111/icad. 12198 those conducting applied conservation science, the only viable approach remains: "all hands on deck" (Thogmartin et al., 2017).

\section{AUTHOR CONTRIBUTIONS}

All authors listed have made a substantial, direct and intellectual contribution to the work, and approved it for publication.

\section{FUNDING}

For JD, RD, and WT, this research was conducted in accordance with official duties as employees of the U.S. Government.

\section{ACKNOWLEDGMENTS}

We thank the U.S. Geological Survey (USGS) Powell Center for Analysis and Synthesis for hosting the Monarch Science Conservation Partnership meetings. This work was supported by the Ecosystems Mission Area and the Land Change Science program at the USGS. We thank M. Steinkamp and M. Wimer, USGS Ecosystems Mission Area, for providing publication support. The findings and conclusions in this article are those of the authors and do not necessarily represent the views of the U.S. Fish and Wildlife Service. Any use of trade, product, or firm names is for descriptive purposes only and does not imply endorsement by the U.S. Government.
Pleasants, J. M., and Oberhauser, K. S. (2013). Milkweed loss in agricultural fields because of herbicide use: effect on the monarch butterfly population. Ins. Cons. Div. 6, 135-144. doi: 10.1111/j.1752-4598.2012.00196.x

Semmens, D. J., Diffendorfer, J. E., Bagstad, K. J., Wiederholt, R., Oberhauser, K., Ries, L., et al. (2018). Quantifying ecosystem service flows at multiple scales across the range of a long-distance migratory species. Ecosyst. Serv. 31, 255-264. doi: 10.1016/j.ecoser.2017.12.002

Thogmartin, W. E., López-Hoffman, L., Rohweder, J., Diffendorfer, J., Drum, R., Semmens, D., et al. (2017). Restoring monarch butterfly habitat in the Midwestern US: "all hands on deck." Environ. Res. Lett. 12:074005. doi: 10.1088/1748-9326/aa7637

Western Association of Fish and Wildlife Agencies (2019). Western Monarch Butterfly Conservation Plan, 2019-2069. Version 1.0. Available online at: https:// www.wafwa.org/Documents\%20and\%20Settings/37/Site\%20Documents/ Committees/Monarch/Western\%20Monarch\%20Butterfly\%20Conservation \%20Plan\%202019-2069.pdf.

Conflict of Interest: The authors declare that the research was conducted in the absence of any commercial or financial relationships that could be construed as a potential conflict of interest.

At least a portion of this work is authored by Jay Diffendorfer, Ryan Drum, and Wayne Thogmartin on behalf of the U.S. Government and, as regards Jay Diffendorfer, Ryan Drum, and Wayne Thogmartin and the U.S. Government, is not subject to copyright protection in the United States. Foreign and other copyrights may apply. This is an open-access article distributed under the terms of the Creative Commons Attribution License (CC BY). The use, distribution or reproduction in other forums is permitted, provided the original author(s) and the copyright owner(s) are credited and that the original publication in this journal is cited, in accordance with accepted academic practice. No use, distribution or reproduction is permitted which does not comply with these terms. 